\title{
Before and after Anorectal Surgery: Which Information Is Needed from the Functional Laboratory?
}

\author{
Maria Witte Frank Schwandner Ernst Klar \\ Department of General, Thoracic-, Vascular and Transplant Surgery, University Medical Department Rostock, Rostock, Germany
}

\section{Keywords}

Anorectal surgery - Anal incontinence .

Digital rectal examination - Anal manometry .

Water holding procedure

\section{Summary}

Background: Anorectal surgery covers a wide spectrum of surgery. Diagnostic workup of anorectal disease is based on clinical examination with basic functional tests followed by more elaborate diagnostic tests. Since the incidence of anorectal disorders increases with age, more patients will present in outpatient clinics, thus underlining the relevance of this topic. Methods: A PubMed literature search was performed using the terms 'anal incontinence', 'anal and rectal surgery', 'functional diagnostics', and combinations of these terms. No restriction regarding publication year or publication type was applied but randomized trials, 'metanalyses', or guidelines were ranked higher. Only articles in English or German were included. Results: The diagnostic value of digital rectal examination, anal manometry and endosonography, the water holding procedure, contrast enema, and incontinence scores is summarized. Conclusion: The article focusses on basic clinical and functional diagnostic tests which can be easily applied in the pre- and postoperative setting to evaluate the postoperative outcome.

(c) 2018 S. Karger GmbH, Freiburg

\section{Introduction}

Anorectal surgery represents a variable portion of procedures in a general surgical department. However, the spectrum of anorectal surgery is wide, ranging from operations for hemorrhoids to inter- sphincteric resection for low rectal cancer; therefore, significant surgical expertise is required. Anal incontinence is on the one hand an indication for reconstructive surgery and on the other hand a well-known complication after anorectal surgery. From the surgeon's viewpoint, it is often desirable to determine function before and after surgery. However, in many situations evaluation of the clinical response to specific surgical manipulation is sufficient.

The classical example is a patient with rectal cancer who has been treated with radiochemotherapy in a neoadjuvant context, who has been operated successfully with a protective ileostomy, and who presents with the desire to take down the ileostomy. Which diagnostic workup should this patient undergo before ileostomy takedown? The focus of this paper is to summarize the basic diagnostic workup which is done before and after anorectal surgery.

\section{Digital Rectal Examination}

Digital rectal examination (DRE) is the basic examination for any patient presenting with symptoms of incontinence, urgency, or the perception of incomplete rectal emptying. However, DRE is not taught routinely since it is often felt as embarrassing by the patient and is thus often rejected. Therefore, this examination is mainly self-educated. A recent survey showed that $30 \%$ of medical students are not sufficiently trained in DRE [1] and that $17 \%$ of students never did a DRE [2]. In many other cases, however, DRE serves as the basis for the subsequent diagnostic workup and, especially when performed by an experienced physician, can predict or preclude further examinations.

DRE is usually done in the left lateral position with the legs flexed. The lateral position is superior to the supine position for exploring the entire rectal circumference, especially when a rectal tumor is being investigated [3]. Furthermore, the patient often prefers not to see the investigator during the examination [3]. The index finger of the right hand is used. In women, with a rather

\section{KARGER}

() 2018 S. Karger GmbH, Freiburg

Fax +497614520714 
shorter anal canal, the ampulla of the rectum can be better explored compared to men with a longer anal canal where it can be difficult to reach the ampulla. Usually the examination is done with resting tone and under squeezing. The basal sphincter tone is determined by the internal anal sphincter, a non-voluntary muscle or visceral muscle [4], whereas the squeezing tone is determined by the external anal sphincter, a somatically innervated muscle [4]. Diminished squeezing tone can originate from many circumstances such as defects of the external sphincter secondary to birth trauma, previous operations, or neurological defects. With the patient straining, a rectocele can be diagnosed $[5,6]$, whereas intussusception is difficult to diagnose by means of DRE [7].

DRE is mandatory in rectal cancer where it discloses location of the tumor, displacement (which is a good parameter for depth of invasion), and the relationship to the anal sphincter. This simple examination still determines today whether the patient can have a sphincter-preserving operation or not.

Previous publications have shown that the 'index finger' is as good as manometry in determining sphincter function [8, 9]. A standardized recording of the DRE in form of the DRESS (digital rectal examination scoring system) score has an excellent correlation with anal manometry [10]. The strength of this scoring is defined by the standardization of the examination but its role in surgical treatment evaluation has not been proven yet. Regarding anal incontinence, DRE has a good sensitivity but low specificity [11], meaning that a normal DRE does not rule out incontinence.

Regarding postoperative examination, DRE can reveal anastomotic dehiscence of a low rectal anastomosis or a colo-anal or an ileal pouch-anal anastomosis.

\section{Water Holding Procedure}

The water holding procedure is a simple, non-invasive examination for evaluation of the sphincter function. A very good indication for the water holding procedure is testing continence in a patient with a loop ostomy before restauration of bowel continuity.

A standardized approach is important for the water holding procedure which can be done by the nurses on the ward. $100 \mathrm{ml}$ water are inserted via a catheter into the rectum, the rectal stump, or the pouch. The patient is asked to hold the water for $20 \mathrm{~min}$ while wearing a sanitary pad. During this time, the patient is allowed to move as usual. After $20 \mathrm{~min}$ the sanitary pad is controlled for wetness (dry/wet) and the patient is asked whether they were able to hold the water for the entire time period. The water holding procedure is positive when the sanitary pad is dry and the patient was able to hold the water.

Interestingly, it is unknown who has invented and introduced this simple test in the clinical routine. It has been described earlier and it is still sometimes being done with liquids other than water. The ease of the method with the possibility to repeat it is a major advantage. In our setting, it corresponds well with rectal manometry and even predicts clinical outcome (unpublished results).

\section{Endosonography}

Endosonography (EUS) can be very helpful in diagnosing perianal fistulas or sphincter defects [11-13]. EUS is often done in patients with perianal manifestation of Crohn's disease. However, complex anal fistulas, especially with supralevatoric extension, can be difficult to detect [14]. In these cases, magnetic resonance imaging (MRI) should be performed. In the German guideline for perianal fistulas, EUS and MRI are judged as equivalent and are suggested for complex or repeat fistulas [15]. Injection of peroxide into the fistula opening can enhance visualization of the fistula tract [16]. Ideally, the surgeon will perform the EUS examination intraoperatively in order to correlate the pre- and intraoperative findings directly.

EUS is mandatory for the diagnosis of rectal carcinoma and differentiation between carcinoma and rectal adenoma [17]. It detects depth of infiltration of the rectal wall and visualizes locally enlarged lymph nodes. Routine repeat EUS can be done after neoadjuvant chemoradiotherapy to prove downsizing [18]; however, it is not done after surgery for routine follow-up. The role of EUS in the 'wait and see' strategy of rectal carcinoma after neoadjuvant chemoradiotherapy has yet to be determined [19].

\section{Anal Manometry}

Anal manometry measures pressure in the anal canal under resting and squeeze conditions. Resting pressure assesses function of the internal anal sphincter while squeeze pressure estimates external anal sphincter function. The capacity of the puborectalis sling is also measured during manometry. It is noteworthy that the values measured are pure numbers and that these results are 'normalized' against a healthy random population which is age-adjusted.

There is a wide range of measuring probes that can be used for anorectal manometry. The most frequently applied technique is perfusion manometry. The manometry probe is inserted and positioned with the tip in the ampulla of the rectum. During manometry the sphincter pressure is continuously measured. The first result is the pressure at rest followed by assessment of the pressure at maximum sphincter contraction. Additionally, the patient can be requested to cough which allows the documentation of this stress reaction. The last measurement includes the anorectal inhibition reflex (fig. 1,2). The shorter female anal canal does not result in reduced pressure per se. However, women have lower (especially resting) pressures compared to men. Furthermore, a reduced pressure combined with full continence has no clinical relevance.

Spontaneous relaxation of the anal canal has been observed in healthy subjects before awakening in the morning and also in patients with an ileoanal pouch during overnight studies associated with leakage [20].

Squeeze pressure can be judged in terms of increase in magnitude compared to the basal resting pressure and in the patient's capability to 'hold the squeezing'. A diminished squeeze pressure can 
Fig. 1. Normal anal manometry of a

61-year-old female patient with rectal carcinoma who underwent low anterior resection with a protective ileostomy. Manometry was done to underline anal continence before ileostomy takedown. Anal manometry measures basal resting pressure of the anal sphincter (1) and then pressure under squeezing (2) and with coughing (3). RAIR (4) denotes for rectal anal inhibitory reflex. A balloon is inflated with $20 \mathrm{ml}$ water simulating distention of the rectal reservoir and leading to relaxation of the internal anal sphincter.

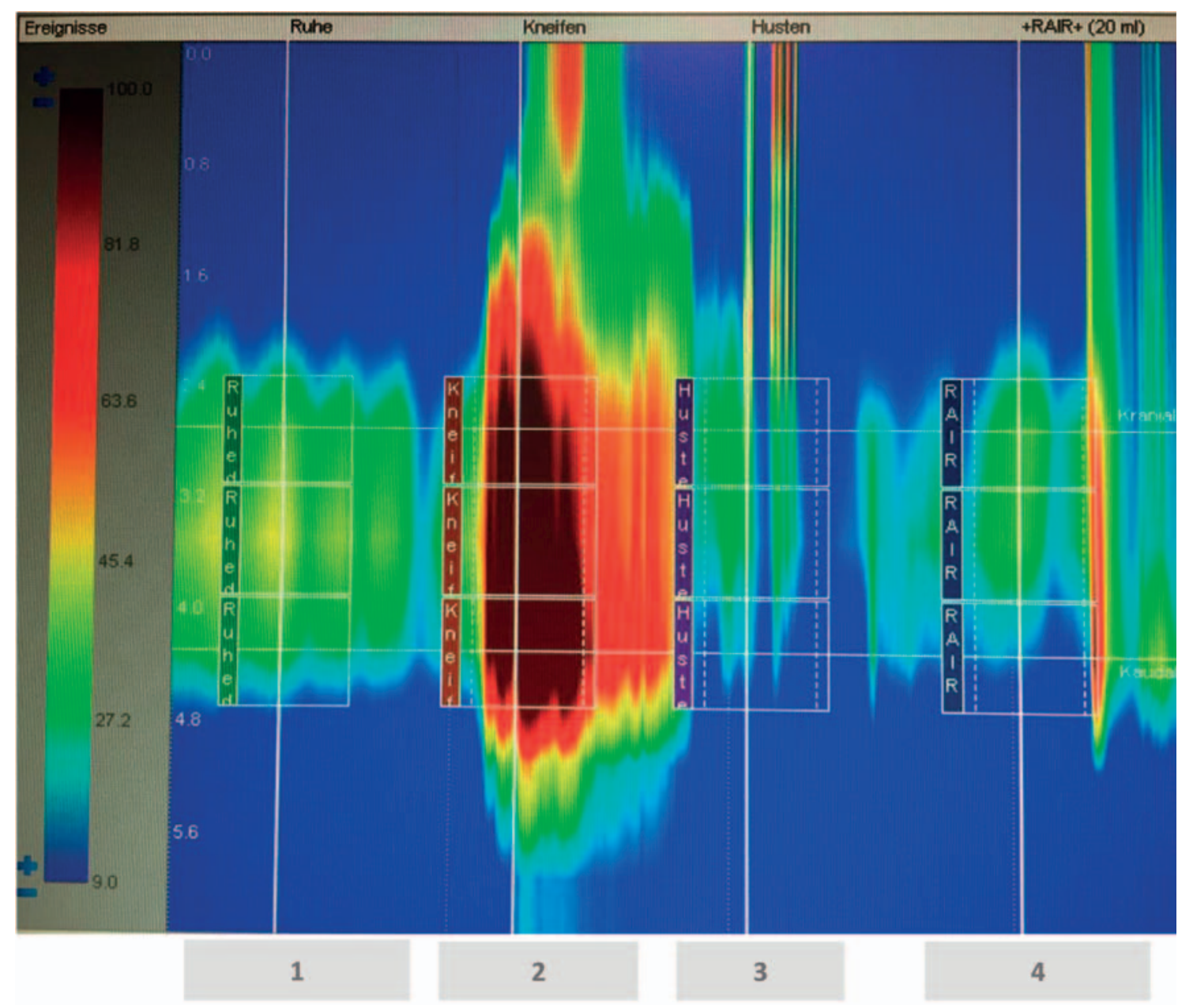

result from muscular or neurological damage which can be further distinguished via EUS. Muscular atrophy of the external sphincter has not been described [20].

Manometry is helpful in various clinical situations since it can be used to evaluate treatment results. Biofeedback for low anterior resection syndrome (LARS) after rectal cancer surgery is a good example [21-23]. Patients with rectal resection show reduced anal pressure up to 1 year after surgery. The level of incontinence correlates with reduced resting pressure levels [24, 25]. Recovery of this function can be monitored via manometry [26]. Manometry can also be helpful in some cases of redo surgery such as hemorrhoidectomy. Although incontinence after hemorrhoidal surgery should be rare, objectivation can be helpful since specific surgical treatments result in distinct postoperative manometric outcome [27]. Rarely, resection of the sensitive anoderm can result in sensory anal incontinence. Advantages of anal manometry are easy feasibility, low cost, and no exposure to radiation.

\section{Contrast Enema}

Protective ileostomy is done in low rectal anastomosis with and without previous radiotherapy, in most cases of proctocolectomy, and in some cases of emergency colonic surgery such as sigmoid perforation. Ileostomy is done to protect the anastomosis and to prevent leak. However, the definition of 'leak' varies widely in the literature and has only recently been clearly defined [28]. Therefore, the leak rate after colorectal anastomosis has also varied widely with rates of up to $25 \%$.

A standard diagnostic workup before ileostomy takedown has not been defined [29], and its usefulness is questioned in general [30]. Depending on the type of surgery and the anastomosis performed, DRE, rectoscopy or proctoscopy, and water-soluble contrast enema are often employed before ileostomy takedown.

Contrast enema are administered by the radiologist. The focus of the examination is the opacification of the anastomosis. A Foley catheter is introduced just above the anastomosis, where the contrast material, usually Gastrografin, is inflated via hydrostatic pressure. In most cases a post-evacuation picture is taken. Most studies do not routinely display the whole colon and only very few depict the passage up to the ileostomy [31]. Occasionally, the examination is done in an anterograde way via opacification of the descending part of the ileostomy [32].

A systematic review on the utility of contrast enema evaluated 1,142 enemas and reported abnormalities in 127 cases, such as leaks, strictures, or fistulas [31]. The sensitivity of the examination 
Fig. 2. a Normal and b pathologic anal manometry of the same patient. He underwent low anterior resection for rectal cancer after neoadjuvant radiotherapy. Digital rectal examination before ileostomy takedown demonstrated a poor anal function with low resting and reduced squeezing pressure. Anal manometry was done to confirm the clinical impression. a Manometry before any therapy. b Reduced and almost absent resting pressure with compensated squeeze pressure. Ileostomy takedown resulted in severe incontinence.
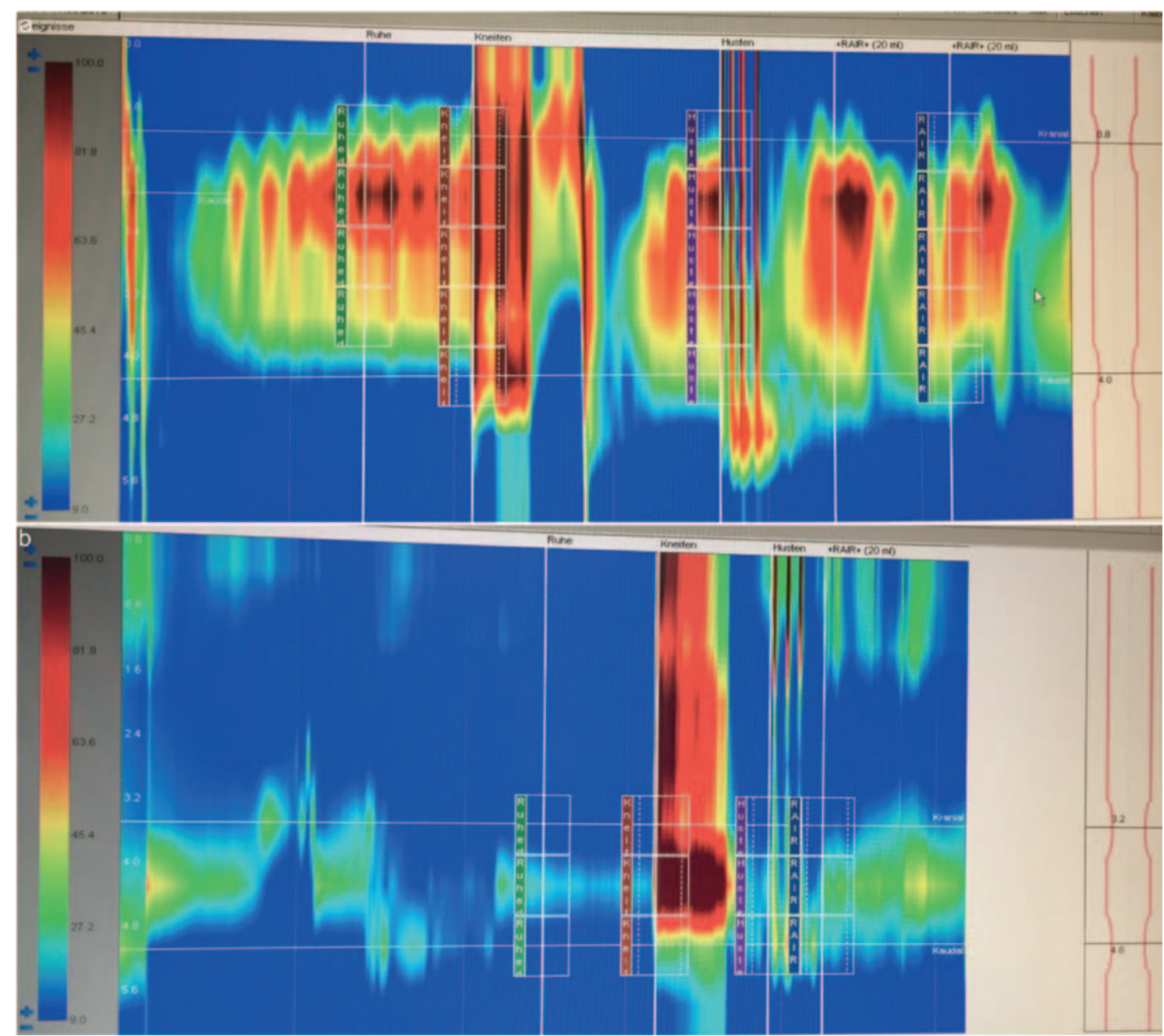

was $80 \%$ and the specificity $95 \%$. In 16 out of 1,142 cases, the enema was normal but stoma reversal was complicated. Therefore, it is rare that a patient will develop a leak at the previous anastomosis if they had a normal enema $[33,34]$.

Side-to-end anastomoses have been shown to be an alternative to a pouch anastomosis [35]. Theoretically, leaks or fistulas from the distal end (the 'Krückstock') cannot be reached with the finger during DRE. Since this end represents the most distal part, clinically inapparent fistulas or leaks due to impaired perfusion can theoretically occur. In these cases, contrast enema can be helpful.

Ileostomy closure can be performed even in the presence of a leak identified by contrast enema, but the outcome is uncertain. In most cases, ileostomy reversal is postponed [19] and a repeat contrast enema is performed. In 11 cases of persistent leak or sinus formation, only 1 patient developed pelvic sepsis after stoma reversal [31]. In general, bowel function in patients with a postoperative leak is poorer compared to non-leak cases, and the oncological outcome is also impaired [36].

Strictures can also be detected via contrast enema especially after proctocolectomy [37]. In low anastomosis after rectal surgery, however, DRE is an equivalent examination [38]. The same holds true for pouch-anal anastomosis after proctocolectomy.
Table 1. Wexner score

\begin{tabular}{llllll}
\hline \multirow{2}{*}{ Type of incontinence } & \multicolumn{5}{l}{ Frequency } \\
\cline { 2 - 6 } & never & rarely & sometimes & usually & always \\
\hline Solid & 0 & 1 & 2 & 3 & 4 \\
Liquid & 0 & 1 & 2 & 3 & 4 \\
Gas & 0 & 1 & 2 & 3 & 4 \\
Wears pad & 0 & 1 & 2 & 3 & 4 \\
Lifestyle alteration & 0 & 1 & 2 & 3 & 4 \\
\hline
\end{tabular}

0 points $=$ perfect continence, 20 points $=$ complete incontinence. never $=0$; rarely $=<1 /$ month; sometimes $=<1 /$ week; usually $=<1 /$ day up to $>1 /$ week; always $=>1 /$ day.

\section{Scores}

Several scores exist such as the Douglas Wong [39], the Pescatori [40], the Wexner [41], the St. Mark's score [42], the Fecal Incontinence Severity Index [43], and the Revised Fecal Incontinence Scale [44]. These scores classify incontinence mainly based on the frequency and type of leakage. The severity of lifestyle alteration, the use of pads, and the frequency of urgency are evaluated by 
some but not all scoring systems. The severity and frequency of incontinence is graded by the patients who can complete the questionnaire on their own.

The scores usually help to grade severity of incontinence and allow to document follow-up after treatment. The choice of scoring system depends on the examiner's preference. The Wexner score is the preferred score by surgeons due to its simplicity and rapid reproducibility (table 1); however, some centers use more than one scoring system or combine it with a quality of life questionnaire such as the Eypasch score $[45,46]$.

A score has also been developed to evaluate symptoms after rectal cancer surgery [39].

\section{Others}

A wide range of other diagnostic tools such as MRI, dynamic MRI, perineal ultrasound as well as evacuation proctography can be applied pre- and postoperatively to investigate the patient [4750]. In many cases, these examinations are initially done to seek for rectocele or intussusception and sometimes constipation or rectal prolapse. However, these examinations are not repeated routinely after surgery to prove surgical or medical success. In one study, de- fecography was used pre- and postoperatively to understand what happens after stapling an obstructive defecation syndrome [51]. These elaborate radiological examinations should be done in selected cases to demonstrate or prove the influence of the operative procedure on the anatomy or in clinical studies.

\section{Conclusion}

Anorectal surgery is performed in a very sensitive organ which requires delicate investigation. The tools used for investigation range from simple DRE to sophisticated dynamic MRI performed in the sitting position mimicking evacuation. However, the basic clinical examinations combining manometry, EUS, and maybe contrast enema cover the major part of the diagnostic workup. More sophisticated radiological workup in form of evacuation proctography or dynamic MRI are done in specialized outpatient clinics.

\section{Disclosure Statement}

The authors have no conflict of interest to disclose.

\section{References}

1 Wong RK, Drossman DA, Bharucha AE, Rao SS, Wald A, Morris CB, Oxentenko AS, Ravi K, van Handel DM, Edwards H, Hu Y, Bangdiwala S: The digital rectal examination: a multicenter survey of physicians' and students' perceptions and practice patterns. Am J Gastroenterol 2012;107:1157-1163.

2 Lawrentschuk N, Bolton DM: Experience and attitudes of final-year medical students to digital rectal examination. Med J Aust 2004;181:323-325.

3 Sabbagh C, Mauvais F, Vecten A, Ainseba N, Cosse C, Diouf M, Regimbeau J-M: What is the best position for analyzing the lower and middle rectum and sphincter function in a digital rectal examination? A randomized controlled study in men. Dig Liver Dis 2014;46:10821085.

4 Parks AG: Modern concepts of the anatomy of the ano-rectal region. Postgrad Med J 1958;34:360-366.

5 Rao SSC, Meduri K: What is necessary to diagnose constipation? Best Pract Res Clin Gastroenterol 2011; 25:127-140.

6 Crane AK, Geller EJ, Myers EM, Fenderson JL, Wells E, Jannelli M, Connolly A, Matthews CA: Implementation of a standardized digital rectal exam to improve the accuracy of rectocele diagnosis. Int Urogynecol J 2015;26:107-111.

7 Karlbom U, Graf W, Nilsson S, Pahlman L: The accuracy of clinical examination in the diagnosis of rectal intussusception. Dis Colon Rectum 2004;47:1533-1538.

8 Hallan RI, Marzouk DEMM, Waldron DJ, Womack NR, Williams NS: Comparison of digital and manometric assessment of anal sphincter function. Br. J Surg 1989;76:973-975.

9 Felt-Bersma RJ, Klinkenberg-Knol EC, Meuwissen SG: Investigation of anorectal function. Br J Surg 1988;75: $53-55$.
10 Orkin BA, Sinykin SB, Lloyd PC: The digital rectal examination scoring system (DRESS). Dis Colon Rectum 2010;53:1656-1660.

11 Pehl C, Birkner B, Bittmann W, et al: Stuhlinkontinenz. Dtsch Arztebl 2000;97:1302-1308.

12 Bader FG, Bouchard R, Keller R, Mirow L, Czymek R, Habermann JK, Fritsch H, Bruch H-P, Roblick UJ: Fortschritte in der Diagnostik anorektaler Erkrankungen. Teil I: Anatomische Grundlagen sowie klinische und neurologische Verfahren. Chirurg 2008;79:401-409.

13 Frieling T: Stuhlinkontinez: Ursache, Diagnostik und Therapie. Dtsch Med Wochenschr 2016;141:12511260.

14 Ong EMW, Ghazi LJ, Schwartz DA, Mortelé KJ: Guidelines for imaging of Crohn's perianal fistulizing disease. Inflamm Bowel Dis 2015;21:731-736.

15 Ommer A, Herold A, Berg E, Farke S, Fürst A, Hetzer F, Köhler A, Post S, Ruppert R, Sailer M, Schiedeck T, Schwandner O, Strittmatter B, Lenhard BH, Bader W, Krege S, Krammer H, Stange E: S3-Leitlinie: Kryptoglanduläre Analfisteln. Coloproctology 2017;39:16-66.

16 West RL, Zimmerman DDE, Dwarkasing S, Hussain SM, Hop WCJ, Schouten WR, Kuipers EJ, Felt-Bersma RJ: Prospective comparison of hydrogen peroxide-enhanced three-dimensional endoanal ultrasonography and endoanal magnetic resonance imaging of perianal fistulas. Dis Colon Rectum 2003;46:1407-1415.

17 Felt-Bersma RJ, Cazemier M: Endosonography in anorectal disease: an overview. Scand J Gastroenterol Suppl 2006;243:165-174.

18 Memon S, Lynch AC, Bressel M, Wise AG, Heriot AG: Systematic review and meta-analysis of the accuracy of MRI and endorectal ultrasound in the restaging and response assessment of rectal cancer following neoadjuvant therapy. Colorectal Dis 2015;17:748-761.
19 Stijns RCH, Tromp M-SR, Hugen N, de Wilt JHW: Advances in organ preserving strategies in rectal cancer patients. Eur J Surg Oncol 2018;44:209-219.

20 Azpiroz F, Enck P, Whitehead W: Anorectal functional testing: review of collective experience. Am J Gastroenterol 2002;97:232-240.

21 Kye B-H, Kim H-J, Kim G, Yoo RN, Cho H-M: The effect of biofeedback therapy on anorectal function after the reversal of temporary stoma when administered during the temporary stoma period in rectal cancer patients with sphincter-saving surgery: the interim report of a prospective randomized controlled trial. Medicine (Baltimore) 2016;95:e3611.

22 Bryant CLC, Lunniss PJ, Knowles CH, Thaha MA, Chan CLH: Anterior resection syndrome. Lancet Oncol 2012;13:e403-e408.

23 Liang Z, Ding W, Chen W, Wang Z, Du P, Cui L: Therapeutic evaluation of biofeedback therapy in the treatment of anterior resection syndrome after sphincter-saving surgery for rectal cancer. Clin Colorectal Cancer 2016;15:e101-107.

24 Rasmussen OO, Petersen IK, Christiansen J: Anorectal function following low anterior resection. Colorectal Dis 2003;5:258-261.

25 Lee SJ, Park YS: Serial evaluation of anorectal function following low anterior resection of the rectum. Int J Colorectal Dis 1998;13:241-246.

26 van Duijvendijk P: Prospective evaluation of anorectal function after total mesorectal excision for rectal carcinoma with or without preoperative radiotherapy. Am J Gastroenterol 2002;97:2282-2289.

27 Izadpanah A, Hosseini S, Mahjoob M: Comparision of electrotherapy, rubber band ligation and hemorrhoidectomy in the treatment of hemorrhoids: a clinical and manometric study. Middle East J Dig Dis 2010;2:9-13. 
28 Rahbari NN, Weitz J, Hohenberger W, Heald RJ, Moran B, Ulrich A, Holm T, Wong WD, Tiret E Moriya Y, Laurberg S, den Dulk M, van de Velde C, Büchler MW: Definition and grading of anastomotic leakage following anterior resection of the rectum: a proposal by the International Study Group of Rectal Cancer. Surgery 2 010;147:339-351.

29 Lauscher JC, Schneider V, Lee LD, Stroux A, Buhr HJ, Kreis ME, Ritz JP: Necessity of subcutaneous suction drains in ileostomy reversal (DRASTAR) - a randomized, controlled bi-centered trial. Langenbecks Arch Surg 2016;401:409-418.

30 Shalabi A, Duek SD, Khoury W: Water-soluble enema prior to ileostomy closure in patients undergoing low anterior resection: is it necessary? J Gastrointest Surg 2016;20:1732-1737.

31 Habib K, Gupta A, White D, Mazari FAK, Wilson TR: Utility of contrast enema to assess anastomotic integrity and the natural history of radiological leaks after low rectal surgery: systematic review and meta-analysis. Int J Colorectal Dis 2015;30:1007-1014

32 Goetz A, da Silva NPB, Moser C, Agha A, Dendl L-M, Stroszczynski C, Schreyer AG: Klinische Wertigkeit der Durchleuchtungsuntersuchung des aboralen Stomaschenkels mittels Kontrasteinlauf. Rofo 2017;189: 855-863.

33 Kalady MF, Mantyh CR, Petrofski J, Ludwig KA: Routine contrast imaging of low pelvic anastomosis prior to closure of defunctioning ileostomy: is it necessary? J Gastrointest Surg 2008;12:1227-1231.

34 Larsson A, Lindmark G, Syk I, Buchwald P: Water soluble contrast enema examination of the integrity of the rectal anastomosis prior to loop ileostomy reversal may be superfluous. Int J Colorectal Dis 2015;30:381-384.
35 Gross E, Möslein G: Pouchanlage und andere Massnahmen zur Verbesserung der Kontinenz nach tiefer anteriorer Rektumresektion mit TME. Zentralbl Chir 2008;133:107-115.

36 Wang S, Liu J, Wang S, Zhao H, Ge S, Wang W: Adverse effects of anastomotic leakage on local recurrence and survival after curative anterior resection for rectal cancer: a systematic review and meta-analysis. World J Surg 2017;41:277-284.

37 Dolinsky D, Levine MS, Rubesin SE, Laufer I, Rombeau JL: Utility of contrast enema for detecting anastomotic strictures after total proctocolectomy and ileal pouch-anal anastomosis. AJR Am J Roentgenol 2007; 189:25-29.

38 Tang C-L, Seow-Choen F: Digital rectal examination compares favourably with conventional water-soluble contrast enema in the assessment of anastomotic healing after low rectal excision: a cohort study. Int J Colorectal Dis 2005;20:262-266.

39 Temple LK, Bacik J, Savatta SG, Gottesman L, Paty PB, Weiser MR, Guillem JG, Minsky BD, Kalman M, Thaler HT, Schrag D, Wong WD: The development of a validated instrument to evaluate bowel function after sphincter-preserving surgery for rectal cancer. Dis Colon Rectum 2005;48:1353-1365.

40 Pescatori M, Anastasio G, Bottini C, Mentasti A: New grading and scoring for anal incontinence. Evaluation of 335 patients. Dis Colon Rectum 1992;35:482-487.

41 Jorge JM, Wexner SD: Etiology and management of fecal incontinence. Dis Colon Rectum 1993;36:77-97.

42 Vaizey CJ, Carapeti E, Cahill JA, Kamm MA: Prospective comparison of faecal incontinence grading systems. Gut 1999;44:77-80

43 Rockwood TH, Church JM, Fleshman JW, Kane RL, Mavrantonis C, Thorson AG, Wexner SD, Bliss D, Lowry AC: Patient and surgeon ranking of the severity of symptoms associated with fecal incontinence: the fecal incontinence severity index. Dis Colon Rectum 1999;42:1525-1532.
44 Sansoni J, Hawthorne G, Fleming G, Marosszeky N: The revised faecal incontinence scale: a clinical validation of a new, short measure for assessment and outcomes evaluation. Dis Colon Rectum 2013;56:652-659.

45 Eypasch E, Williams JI, Wood-Dauphinee S, Ure BM Schmülling C, Neubauer E, troidl H: Gastrointestinal Quality of Life Index: development, validation and application of a new instrument. Br J Surg 1995;82: 216-222.

46 Rusavy Z, Jansova M, Kalis V: Anal incontinence severity assessment tools used worldwide. Int J Gynaecol Obstet 2014;126:146-150.

47 Maglinte DDT, Bartram CI, Hale DA, Park J, Kohli MD, Robb BW, Romano S, Lappas JC: Functional imaging of the pelvic floor. Radiology 2011;258:23-39.

48 Bader FG, Bouchard R, Lubienski A, Keller R, Mirow L, Czymek R, Habermann JK, Bruch H-P, Roblick UJ: Fortschritte in der Diagnostik anorektaler Erkrankungen. Teil II: Radiologische Verfahren. Chirurg 2008;79: 410-417.

49 Maglinte DDT, Hale DS, Sandrasegaran K: Comparison between dynamic cystocolpoproctography and dynamic pelvic floor MRI: pros and cons: which is the 'functional' examination for anorectal and pelvic floor dysfunction? Abdom Imaging 2013;38:952-973.

50 Keller J, Layer P: Intestinal and anorectal motility and functional disorders. Best Pract Res Clin Gastroenterol 2009;23:407-423.

51 Boenicke L, Kim M, Reibetanz J, Germer C-T, Isbert C: Stapled transanal rectal resection and sacral nerve stimulation - impact on faecal incontinence and quality of life. Colorectal Dis 2012;14:480-489. 